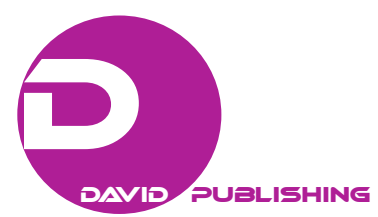

\title{
The Normative Value of Truth and the Problem of Lie
}

\author{
Marta Szabat \\ Jagiellonian University Medical College, Kraków, Poland
}

\begin{abstract}
The article concerns the normative value of truth in relation to lie. Based on arguments derived primarily from ancient philosophers (Eubulides, Plato, Aristotle), medieval philosophers (St. Augustine, St. Thomas Aquinas), the thinker of the Renaissance-Machiavelli, the main philosopher of the Enlightenment-Kant, the 19th-century author of Beyond Good and Evil (Nietzsche), and contemporary thinkers such as Derrida and Lacan, the author considers here truth as a normative value. Lying is relative to the truth, and it has no ontological legitimacy, even it cannot exist without truth itself. In the final part of the article, the author concludes that the truth, however, cannot lead to clearly bad effects, be harmful or cause pain disproportionate to the effects caused by lie. Therefore, it must coexist with the good - the other parent value. Only when both values complement each other can we talk about the normative value of truth. The truth should be correlated with other values on which value systems are based, especially the good of a person or group of persons, avoiding harm towards others, and the protection of a person's health and life. Only then can the truth be appropriate to use. It is not an immovable foundation, but a dynamically functioning value, in which language and the ethical (active) dimensions provide the value of the specified situations. The truth can be a double-edged sword: It may hurt, but it can defend itself. The latter function seems to be the most important type of the normativity of truth.
\end{abstract}

Keywords: truth, lie, normativity

\section{Introduction}

The truth is not only a condition of judgment, but also a value which binds a given culture together. The normativity of moral ideas of truth builds communities and determines their direction. Theoretically, the value of truth is much higher than that of a lie. In practice, however, lie can be useful, desirable, easy or difficult to justify, or can serve good purposes, etc.. The article concerns the normative value of truth in relation to lie. Based on arguments derived primarily from ancient philosophers (Eubulides, Plato, Aristotle), medieval philosophers (St. Augustine, St. Thomas Aquinas), the thinker of the renaissance-Machiavelli, the main philosopher of the Enlightenment-Kant, the 19th-century author of Beyond Good and Evil (Nietzsche) and contemporary thinkers such as Derrida and Lacan, the author considers here truth as a normative value.

\section{The Problem of Lie_-Preliminary Considerations}

Since the time of Plato, lie has been closely related to consciousness and to the good or bad intentions of the person lying. The ancient Greek philosopher divided it into the conscious lie (harmful and harmless) and the unconscious lie. This division, with some modifications, still persists to today. Plato believed that the conscious lie is better than the unconscious because the liar, who knows the truth, is closer to it, which puts him in a better

Marta Szabat, Ph.D, Faculty of Health Science, Jagiellonian University Medical College. 
position in relation to a person who is unaware of the facts (Plato, 1982). However, it is possible to resent the fact that a person with expertise in a certain field - in everyday life or in a scientific field — is lying, despite the fact that he knows the truth.

The most worthy of reprimand seems to be the conscious and harmful lie. In this case, a liar's motivations can be divided into three major groups. Firstly, such liars lie for their own benefit (material or immaterial); such motives are listed by many thinkers engaged in analysis of the phenomenon of lie (St. Augustine, 1937; Aquinas, 1981; Kant, 1968). Secondly, the liar can lie out of fear or under pressure. Thirdly, a person may hide the truth and lie because he or she wants to deliberately harm others. Undoubtedly, intentions play a key role in assessing moral lies. In the mature medieval moral philosophy of Thomas Aquinas, people gain a specific structure of lies as a manifestation of human action. Every human action is based on consciousness and will, which means that an action consists of the objective result of the action, the intention, and the circumstances in which the action occurs. Then the action can be evaluated as blameworthy when its effect is bad. In Aquinas's thought, the effect of lie determines its rank. If it involves a high cost for the person who is deceived, then we can say that lying is clearly wrong. It is worth noting that the medieval thinker evaluates lie in an unambiguously negative way. The value of truth is placed clearly higher by him than that of lies (Aquinas, 1981).

Taking into consideration these two concepts of lie (Plato \& Thomas Aquinas), it is possible to perceive the real dependency of lie on the truth. The truth is presented by the philosophers as an objective fact, a real normative value independent of any historical conditions and of agents who could tell the truth or hide it. The truth seems to be much more significant than lie and is closely associated with consciousness. However, in Plato himself it can be found that at least two planes on which the boundaries between "evil" lies and "good" truth are blurred. The first concerns harmless and conscious falsehood, useful both in the education of children or the young or unaware, as well as in bringing someone closer to a truth which is difficult to understand. Through myth or legend, one can get to the truth indirectly, slowly, with feeling and understanding of the difficulties in the assimilation of full and complete knowledge. In this case, lie serves a "good" function; it has a good purpose. The second perspective relates to the role of the useful lie, which can be useful in society and especially in politics, where lie, out of necessity, so to speak, can gain and maintain power in the name of good purposes. This last topic was continued in the Renaissance in Niccolo Machiavelli's The Prince, where lie gained the status of a necessary way to achieve a lofty goal: unification of the country (Machiavelli, 1532). It is worth noting that Machiavelli's work seems to be timeless, and remains well-suited to the description of contemporary political life and to the analysis of the mechanisms of power currently practiced.

On the one hand, the social dimension of lies contributed to the blurring of the boundaries between lie and the truth. On the other hand, it can be said that it has also revealed the phenomenal, phenomenological nature of lie as something which has no essence. This sort of nature can be seen in the ancient paradox of the liar derived from Eubulides, which emphasizes that the liar is a liar only if he lies and so long as he lies (Wheeler III, 1983). A person who lies cannot permanently be a liar unless this involves a conscious and specific choice of lifestyle based on lies. Perhaps a good illustration for this kind of choice would again be the political life and the decisions of certain politicians. In this case, the randomness of lies would change to a permanent predisposition towards lying, as indicated by Aristotle, while warning against the danger of this type of choice. This decision is chosen lying as a lifestyle and then become skilled in lying, first to others and then to oneself (one seems to be inseparable from the other) does, in the long run, more harm to the liar than the person who is deceived. Selecting 
lie, the liar consciously sets himself on the side of appearances, illusions, and falsehood (Aristotle, 1999). It is difficult to even imagine how the liar can keep himself in a state of permanent falsehood, in which it is very difficult to build value, above all in his or her own personal life.

\section{The Truth as a Certain Level of Objectivity and Its Reference to Lie}

Jacques Derrida stresses that it is not possible to construct upon lie either science or any kind of knowledge that requires constant comparison of arguments made against hypotheses (Derrida, 2012). Therefore, the truth would be necessary not only as a moral value, but also as a certain level of objectivity. However, establishment of such a level is done not only on the objective scientific or social level. This objectification of truth plays an important role in the development of subjective mechanisms for determining the subjective conditions of both the world and the subject. On the one hand, true means "ready to verify", "suitable for verification", and maintaining order when what is set up has been built on shaky foundations. On the other hand, psychological studies and psychoanalytic theories point to the fact that illusion and falsehood form the most primal adaptive structure on a subjective and objective (social and cultural) level for each and every person. Deformation of facts seems be necessary for people to survive. Clashing with reality could make daily functioning impossible.

Jacques Lacan distinguishes the real (le réel) from the reality (la réalité). The real strives for the truth of the subject. Reality, meanwhile, results from cultural and social norms and is related to notions of the subject, to the roles that the agent assumes. It may be noted that the real is beyond the order of presentation which dominates in the order of reality. People prefer reality to the real. However, sometimes they have to confront the real as the absolute truth about the reality in which they usually operate (Lacan, 1973).

Lie does not play a similar role to the truth. In lie, every fact or event is separate, subjective, historical, and has situational meaning. Not only does lie always refer to a particular type of the truth, to areal situation or event, to spoken sentences, but it also deforms all of them. The deforming function of lie fulfills its role even when it is spoken in deformed reality (for example in the reality of a totalitarian society based on propaganda), or even when it relates to distorted fact. In this case, lie doubles this sort of reality, in principle upholding its "mythology". Deformation may be broken only by the truth, truthfulness, and confrontation with the facts.

The normative value of truth lies precisely in the fact that it reflects appearance like light reflecting off a mirror, revealing the apparent nature of reflections by gliding over things and faces. Lie, like a reflection, exists only thanks to what it can be related to. It must have a reference point. As such, it does not include enough of reality to completely replace the truth. Even though lie affects social awareness all over the world and at each step occurs as a function of manipulation, it constantly clashes with the truth, keeping its normativity intact. Truth is power. This is perhaps also because, even today, many people give their lives for the truth. It is a necessary foundation for a variety of reflections, illusions, falsifications, hypocrisies, misunderstandings, deformations, and misrepresentations. It is a reference point for all decisions. Without the truth, the sphere of phenomena would be impossible. Thus, by its very essence, the truth must be normative.

Friedrich Nietzsche believes that man by his very nature is a great counterfeiter who deforms the existing world by the illusion of exploring it. Mankind needs to know, and knowledge gives him a sense of control over reality. It tames the world in the sense that it introduces the illusion of a lack of mystery and fullness of 
knowledge. However, the world cannot be fully known, but this mankind does not notice. The building of culture and the Western civilization is therefore based on false premises. A similar idea of human insignificance was also expressed by Blaise Pascal, who pointed to the fragility of human existence. However, at the same time Pascal emphasized the greatness of man because of his ability to think.

On the one hand, Nietzsche's skepticism is based on imperfect human cognitive capabilities. But on the other hand, it refers to humankind's ontological status itself, which is based on transience. Because of this, man wants to confuse his own destiny, and creates the illusion of eternal worlds, the immortal soul, etc.. According to Nietzsche, these dreams are only illusions, a false attempt to deceive human nature. The truth about man lies elsewhere - in his inability to know the nature of life and the fact that he should try to exceed himself and not persist in a world of illusion which he himself created. However, it seems that the truth about mankind should be sought somewhere else. Nietzsche indicated a certain way of unmasking the conditions of culture and civilization. The fact is that the truth of his thought not only demonstrates the standard features of the truth, but also points to the truth as normativity as such as absolute, non-conformist. It is in the light of truth that specific rules are introduced, distortions are revealed. The truth thus reveals its absolute face.

In Nietzsche's thought, there appear reasons to conclude that man is notable to bear the truth about himself, which is the reason why he should disappear in favor of the over-man (Übermensch). Man likes to lie to such an extent that through the ages he has produced cultural mechanisms which train people to expend little intellectual, creative, and spiritual effort. In fact, the goal of man is a convenient and easy life. Any individual outstanding agents who take the effort of truth upon themselves are stigmatized and considered to be different, odd, and mismatched. The truth of man is no different from a lie. Only by going beyond illusion, by severing ties with it would a fundamental and radical chance be provided: the truth about the over-man (Nietzsche, 1976).

It seems that the power of the truth, the strength of facts as well as effects of the truth are revealed in Nietzsche's thought. In this way, the normativity of truth comes to the fore. Lie generates illusion; it allows the existence of apparent values and strengthens reluctance to verify. On the one hand, a person can deceive him or her and protect him or her from the truth about his or her own capabilities, life, etc.. It gives him or her the illusion of security based on habituation to the existing world and to what he or she has achieved. On the other hand, the illusion of lie overpowers the abilities of both the individual and larger social groups. Without requiring mental effort, lie strengthens habit. The truth, meanwhile, seems to have the power to mobilize. The possible pain and suffering associated with the truth may ultimately bring more advantages than disadvantages. The condition for this is the strength to endure the truth, accept and admit it, and then use the resulting facts to good purposes. The power of truth would appear as double in its relations with the good.

Therefore, the normativity of truth may be non-negotiable, categorical, without exception. But here we can pose the question of whether this sort of truth is still the right truth. Can the absolute truth, in other words, still be good and remain one of the highest values? In this regard, all those reflecting on the normativity of truth as value remain divided. On the one hand, the position according to which a duty to truthfulness applies absolutely is characteristic of the philosophies of both Thomas Aquinas and Immanuel Kant. On the other hand, most thinkers are in favor of exceptions to the imperative of truthfulness when other values are threatened. The ancient philosophers, such as Plato, expressed the belief that a lie can perform useful functions and serve the good. St. Augustine divided lying into eight types of lies, based on the criterion of diminishing evil, thus suggesting that some lies are not equal to others. 
Contemporary thinkers, especially after the events of the Second World War, rationalized exceptional situations in advance in which using lies would protect human life or human property. It seems that in situations in which any ethics are suspended when it comes to human life, health, and safety, all measures, including a lie that could prevent suffering, protect human life, health, and property, are good in the sense that they serve good purposes. Here this article is not intend to propagate the Machiavellian principle of the "end justifies the means". On the contrary, it is attempting to emphasize that from principles of truthfulness there are exceptions for the sake of protecting other values, which in any given historical period may be jeopardized. Machiavelli sanctioned lying on a global and objective scale, the Prince, in order to achieve a good aim, which was the unity of the Italian principalities and thus unification of the country, can use lies voluntarily and freely in order to gain power and to maintain it. The author argues that nowadays, this sort of lie can do more harm than good. The unity of the country, which was the most important value for the Prince, does not contain in itself, as a value, a sufficiently high level of the good. What is more, people are able to estimate the value of the good only for groups of individuals. In Machiavelli's work, it is not possible to find any reflections on this issue. In his thinking, lying gains a status similar to that of a normative value. It is worth emphasizing that the author of The Prince was not able to predict the effects of such a policy in the long run. He even warned the Prince against false advisors. He would need advisors who spoke the truth, in order not to have his world collapse around him thanks to sycophants.

The end does not justify the means, and the truth has an undoubtedly normative status. However, the truth must coexist with the good evaluated as such in a particular historical situation, that is, in a given case. The estimation of the positive and negative effects of truthfulness and falsehood helps to better recognize the good in the situation than a priori assumptions about the robustness of the truth.

\section{The Normative Value of Truth and Its Relation to the Good}

It seems that the normativity of the truth is not uniform. On the one hand, the truth can hurt, can cause pain and suffering. On the other hand, the truth is essential to ensure mankind a sense of security, and it is necessary in the rule of law, where the citizen has the right to information. This last premise should be true, but it is not enough. The truth cannot be cruel. It should be adjusted for both the age of the person being informed (we inform children differently from young adults, who in turn we inform differently from people who are mature, and those differently from people who are specialized in the subject to which the information refers, and the elderly differently as well), as well as to the situation. A good example here might be patients' rights and different models of medicine, according to which the patient is treated appropriately, giving him complete information as to his state of health (although the quality of the information depends on the type of disease and the patient's situation or unpreparedness to hear the truth about his illness) or by withholding the truth for the sake of the patient (a particularly clear example may be the widely-criticized paternalistic model). The truth in medicine is the appropriate patient management strategy — on the one hand, the truth can deprive the patient of hope, but on the other hand, it can give the patient strength to fight the disease and, in extreme cases, when the patient can no longer be saved, the truth about the disease allows him to plan the final moments of life and choose how best to use them.

Truth cannot be an end in itself. It is impossible to accept the rule that the truth applies in all conditions, regardless of people's good or the situation. The truth is an extremely important value, it has a normative dimension, people can build on it, but it cannot pointlessly cause harm through the very fact that it appears. The 
truth which appears as a function of defense can in this case be compared to the defensive lie, that is, one in which people want to protect an intangible asset (for example, someone's life or health) or material asset (for example, our or another's property). The truth in this kind of functionality enhances the value of the message, and the defensive lie is relativized to the value of the good, which forms the superior value. The example situation, in which we indicate a thief revealing the truth about his deed, is very important because it allows us to return the good in the form of property to a person deprived of it. The truth is here a sort of means to an end which does not raise any moral dilemmas, unless circumstances complicate the question of the good of the individual. Let us suppose that the thief is the father of a poor and destitute family, who stole for the good of loved ones. The person robbed is a mob boss or an unscrupulous banker earning a fortune by cheating customers. In this case, the truth would not be an obvious value on account of the problematic nature of the good which it would lead to. From the other side, lying to protect someone's life in a wartime situation-an example often used is the Second World War, when Jewish people hid from the occupying forces and those who concealed them lied to protect them and their lives. In this case, lie is relativized to the value of the good and through the prism of the latter we make a moral judgment. The actual well-being of a person or group of people enables and helps to properly assess both the value of truth and lies. In the latter case, the good helps rather in justifying lies, not elevating them to the status of normative rules of social intercourse. It is different from the truth. Depending on the effects of truthfulness, that is, on the good, the truth is either relative in terms of the good or confirms its normative value, enhancing the value of the good.

It also seems that truth which can hurt, kill, destroy, and strengthen hatred, without leading to long-term good based on reasonable assumptions, in some way leads to the suspension of its normative status. The ancient Greeks expressed a similar idea in the kalokagathia — kaloskagathos, that is, a beautiful and good man who combines the highest values of its action, which Plato distinguished as the Good and Beauty.

\section{Conclusion}

Normativity of truth should always be confirmed by a second basic ethical value, which is the good. Only then does the truth not only maintain its normative status, but it also reveals the strength inherent in it. The truth cannot lead to clearly bad results. There may also be a more important value or one that is greater than the good. Both values must complement each other. The truth should be correlated with other values on which value systems are based, especially those such as the good of a person or group of persons, avoiding harm towards others, and protection of health and life. Only then will appropriate use of the truth be possible. It is not a fixed and immovable foundation, but a dynamically functioning value, in which linguistic and ethical (active) dimensions give value to specified situations. The truth can be a double-edged sword: It may hurt, but it can defend itself. The latter function seems to be the most important type of normativity of the truth.

\section{References}

Aquinas, T. (1981). The summa theologica. First complete American edition in 3 volumes. Literally translated by Fathers of the

English Dominican Providence, vol. 20. London: Burns, Oates, \& Washbourne, 1912-1936; reprinted in five volumes. Westminster: Christian Classics.

Aristotle. (1999). Nicomachean ethics. (T. Irwin, Trans.). Indianapolis: Hackett Publishing Company.

Derrida, J. (2012). Histoire du mensonge. prolégomènes. Paris: Galilée.

Kant, I. (1968). Über ein vermeintliches Recht aus Menschenliebe zu lügen. In K. Werke (ed.), Akademie Ausgabe. Band VIII (pp. 423-430). Berlin: de Gruyter \& Co.

Lacan, J. (1973). Tuché et automaton. In J. A. Miller (Eds.), Le seminaire de Jacques Lacan (pp. 63-75). Le quatre concepts 
fondamentaux de la psychanalyse 1964, vol. 11. Paris: Édition du Seuil.

Machiavelli, N. (1532). The prince. (W. K. Marriott, Trans.; J. Bickers, D. Widger, and Others, Produced.). The Project

Gutenberg EBook of The Prince, 2006-2012. Available from http://www.gutenberg.org/files/1232/1232-h/1232-h.htm

Nietzsche, F. (1976). On truth and lie in an extra-moral sense. In W. A. Kaufman (Trans.), The portable Nietzsche. New York:

Viking Press.

Plato. (1982). Hippias major. (P. Woodruff, Trans.). Indianapolis: Hackett Publishing Company.

St. Augustine. (1937). De mendacio; Contra mendacium. Oeuvres de Saint Augustin (vol. 2). Paris: Desclée De Brouwer.

Wheeler III. (1983). S. C., Megarian paradoxes as Eleatic arguments. American Philosophical Quarterly, 20(3), 287-295. 